\title{
Die Textualisierung der Religion
}

\author{
Hrsg. v. Joachim Schaper
}

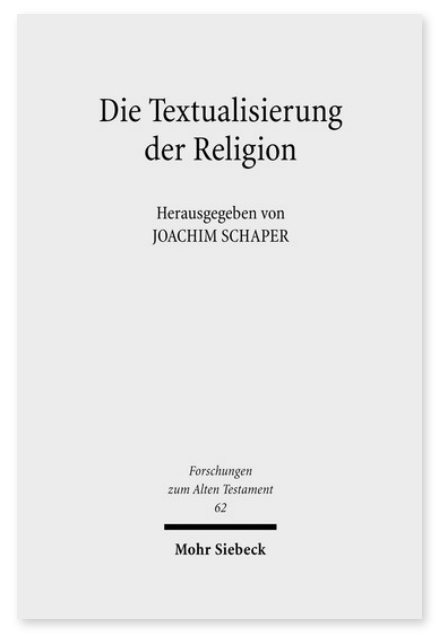

2009. XI, 307 Seiten. FAT 62

SBN 978-3-16-151103-5

DOI 10.1628/978-3-16-151103-5

eBook PDF 109,00€

ISBN 978-3-16-149730-8

Leinen $109,00 €$
Die Bedeutung des Schreibens, der Schriftkultur und des Verhältnisses zwischen 'orality' und 'literacy' sind für die Entwicklung von Religionen von grundlegender und gar nicht zu überschätzender Bedeutung. Es ist darum sinnvoll, die Religionsgeschichte aus der Perspektive der Mediengeschichte zu untersuchen.

Die Beiträger dieses Bandes demonstrieren dies an den Beispielen der Textualisierung der judäischen JHWH-Religion in der spätvorexilischen, exilischen und frühnachexilischen Zeit, ägyptischer und mesopotamischer Traditionen, des hellenistischen und des rabbinischen Judentums sowie hinduistischer und buddhistischer Konzepte. Zu den wichtigsten Ergebnissen der in diesem Band versammelten Untersuchungen gehört die Einsicht in die interkulturelle Vergleichbarkeit des Phänomens der Textualisierung, die über Judentum, Christentum und Islam hinausreicht. Der Band schließt mit Überlegungen zum Zusammenhang zwischen der Textualisierung der israelitischen Religion und dem Durchbruch des Monotheismus in der spätvorexilischen und exilischen Zeit und setzt sich dabei nicht zuletzt mit einer These Jan Assmanns auseinander, die in letzter Zeit viel Staub aufgewirbelt hat und der Korrektur bedarf.

Inhaltsübersicht

Einleitung

Teil I: Textualisierung in Ägypten und Mesopotamien J. F. Quack: Redaktion und Kodifizierung im spätzeitlichen Ägypten: Der Fall des Totenbuches - W. Roellig: Aspekte der Archivierung und Kanonisierung von Keilschriftliteratur im 8./7. Jh. v.Chr. Teil II: Textualisierung im alten Israel und in der fruehjuedischen und rabbinischen Literatur

J. Renz: Die vor- und außerliterarische Texttradition. Ein Beitrag der palästinischen Epigraphik zur Vorgeschichte des Kanons B. Ego: »In der Schriftrolle ist für mich geschrieben« (Ps 40,8). »Mündlichkeit« und »Schriftlichkeit« im Kontext religiösen Lernens in der alttestamentlichen Überlieferung - C. Hardmeier: Zur schriftgestützten Expertentätigkeit Jeremias im Milieu der Jerusalemer Führungseliten (Jeremia 36). Prophetische Literaturbildung und die Neuinterpretation älterer Expertisen in Jeremia 21-23 - K. Schmid: Nebukadnezars Antritt der Weltherrschaft und der Abbruch der Davidsdynastie. Innerbiblische Schriftauslegung und universalgeschichtliche Konstruktion im Jeremiabuch - S. Schorch: Communio lectorum. Die Rolle des Lesens für die Textualisierung der israelitischen Religion - L.-S. Tiemeyer: Two Prophets, Two Laments and Two Ways of Dealing with Earlier Texts - B. Ego: Im Schatten hellenistischer Bildung. Ben Siras Lern- und Lehrkonzeption zwischen Mündlichkeit und Schriftlichkeit - G. Stemberger: Mündliche Tora in schriftlicher Form. Zur Redaktion und Weitergabe früher rabbinischer Texte

Teil III: Textualisierung im Hinduismus und im Buddhismus

G. Flood: Text Reception and Ritual in Tantric Scriptural Traditions - W. Tuladhar-Douglas: Writing and the Rise of Mahayana Buddhism

Statt eines Epilogs

Joachim Schaper: »Scriptural Turn« und Monotheismus. Anmerkungen zu einer (nicht ganz) neuen These

Joachim Schaper Born in 1965; 1993: PhD (Cantab); 1999: Habilitation; 2005-12: Reader, then Professor in Hebrew, Old Testament and Early Jewish Studies; since 2012: Professor of Hebrew and Semitic Languages at the University of Aberdeen; 2016-19: President of the International Organization for the Study of the Old Testament.

Jetzt bestellen:

https://mohrsiebeck.com/buch/die-textualisierung-der-religion-9783161511035?no_cache=1

order@mohrsiebeck.com

Telefon: +49 (0)7071-923-17

Telefax: $+49(0) 7071-51104$ 